\title{
Employees Sick-Listed with Mental Disorders: Who Returns to Work and When?
}

\author{
C. A. M. Roelen · G. Norder • P. C. Koopmans • \\ W. van Rhenen · J. J. L. van der Klink • \\ U. Bültmann
}

Published online: 24 March 2012

(C) The Author(s) 2012. This article is published with open access at Springerlink.com

\begin{abstract}
Purpose To investigate return to work (RTW) in employees sick-listed with mental disorders classified according to the International Classification of Diseases (ICD). Methods Sickness absences (SA) medically certified as emotional disturbance (ICD-10 R45) or mental and behavioral disorders (ICD-10 F00-F99) were retrieved from an occupational health service register. RTW was associated with age, gender, and socioeconomic position (SEP) by parametric survival analysis. Results Emotional, neurotic, somatoform, stress-related, and mood disorders encompassed $94 \%$ of all mental SA. Employees with emotional disturbance had the highest RTW rates: after 1 year $95 \%$ had resumed work and after 2 years $98 \%$ compared to 89 and $96 \%$ of employees with neurotic, somatoform and stress-related disorders, and 70 and $86 \%$ of employees with mood disorders. The probability of
\end{abstract}

C. A. M. Roelen · G. Norder · P. C. Koopmans ·

W. van Rhenen

365 Occupational Health Service, PO Box 85091,

3508 AB Utrecht, The Netherlands

C. A. M. Roelen · G. Norder · J. J. L. van der Klink ·

U. Bültmann

Department of Health Sciences, Community and Occupational Medicine, University Medical Center Groningen, University of Groningen, PO Box 196, 9700 AD Groningen, The Netherlands

C. A. M. Roelen $(\square)$

365ArboNed, PO Box 158, 8000 AD Zwolle,

The Netherlands

e-mail: corne.roelen@365.nl

W. van Rhenen

Center for Human Resource, Organization and Management Effectiveness, Business University Nyenrode, PO Box 130,

3620 AC Breukelen, The Netherlands
RTW decreased after 1 month of SA due to emotional disturbance, 2 months of SA with neurotic, somatoform and stress-related disorders, and 3 months of SA with mood disorders. Women resumed their work later than men. Young employees presenting with emotional disturbance, neurotic, somatoform, and stress-related disorders had earlier RTW than older employees and low-SEP employees had earlier RTW than high-SEP employees. Conclusions RTW rates and probabilities differed across categories of mental disorders. Age and SEP were associated with RTW of employees with emotional, neurotic, somatoform, and stress-related disorders, but not with RTW of employees experiencing mood disorders. To maximize the likelihood of RTW, a focus on RTW is important in the first months after reporting sick with mental disorders.

Keywords Absenteeism - Mental disorders - Psychiatric disorders · Return to work - Sick-leave $\cdot$ Sickness absence

\section{Introduction}

Mental disorders occur frequently and account for an increasing burden of disease in developed countries [1-2]. The prevalence of mental disorders peaks during working age, which makes them a major cause of sickness absence [3-4]. Employed people with mental disorders lose three times more work days in a 12-months' period compared to people without mental disorders [2]. Furthermore, mental disorders are associated with an increased risk of disability pensioning [5-9]. The Organization for Economic Co-operation and Development reported that mental disorders account for up to one-third of disability pension awards in western European countries [10]. 
The occupational rehabilitation and return to work (RTW) of employees with mental disorders are topical issues in occupational healthcare. Recently, Nielsen et al. [11] investigated RTW rates of employees with longterm ( $>3$ weeks) sickness absence (SA) due to mental health problems and reported that $26 \%$ of Danish employees had resumed work at 10 weeks, $56 \%$ at 20 weeks, $73 \%$ at 30 weeks, and $81 \%$ at 40 weeks after reporting sick; $12.7 \%$ of employees had not resumed work after 1 year and applied for disability benefits. The authors based their results on employee-reported mental health problems, which were neither medically verified nor categorized according to an international classification system. Therefore, it is difficult to use such data for comparative studies on RTW of employees with mental disorders across countries. All the more because comparative studies are hindered by differences in (occupational) healthcare and social security systems between countries.

In Norway, RTW after long-term ( $>2$ weeks) SA due to mental disorders was classified according to the International Classification of Primary Care (ICPC). Overall, $25 \%$ of employees resumed work within 1 month of calling in sick, $52 \%$ within 3 months, and $73 \%$ within 6 months; $8.5 \%$ had not resumed work after 12 months and were transferred to other forms of compensation [12]. Employees sick-listed with crisis reactions (ICPC P02 and P25) had the highest RTW rates and those sick-listed with psychoses (ICPC P72, P73 and P98) the lowest RTW rates at any time within 12 months of reporting sick. Employees with neurotic conditions (ICPC P04, P06-10, P20, P27-29, P75, P78-80, and P99) and depressive disorders (ICPC P03, P76, and P77) had similar RTW rates, which were higher than the RTW rates of employees with anxiety conditions (ICPC P01 and P74) and substance dependence (ICPC P15-P19).

The Norwegian data originate from the late nineties and must be considered outdated, because work has changed considerably in the last decades [13].

The labour force in most European countries has become increasingly flexible due to both low employment rates in the nineties when job creation was a priority, and globalisation where it is important to adapt swiftly to the economic market. This increase in flexibility results in more temporary employment and reduced job security, which impact on employees' mental health [14-16]. In addition, the labour participation of women has increased and the labour force has gradually aged since the nineties [13]. Besides these labour force changes, work itself has intensified. The European Working Condition Surveys have shown that work is carried out faster while the level of control over work has stabilized [13, 17-18]. In addition, more Europeans work in (high-knowledge) services with new technologies in jobs with increasing cognitive demands.

These labour force and work changes may have affected the epidemiology of SA and RTW of employees with mental health disorders. Therefore, the purpose of this study was to update data on RTW of employees with longterm ( $>3$ weeks) SA due to mental disorders, classified according to the 10th version of the International Classification of Diseases (ICD-10). Subgroup analysis for each ICD-10 category will provide insight in RTW rates and RTW probabilities for different types of mental disorders.

\section{Methods}

365/ArboNed is an occupational health service in The Netherlands that is contracted by more than 72,000 companies nationwide to provide their employees with occupational healthcare. Occupational physicians (OPs) working for 365/ArboNed record SA in the 365/ArboNed register with a diagnosis according to the 10th version of the International Classification of Diseases (ICD-10) issued by the World Health Organization [19]. The 365/ArboNed register contains the SA data and diagnostic codes of one million employees of whom $1 \%$ works in the agricultural sector, $20 \%$ in the industrial sector, $58 \%$ in the private sector and $21 \%$ in the public sector as compared to 4, 23, 50 and $23 \%$ respectively of the Dutch workforce.

\section{Sickness Absence Policies and Practices}

In The Netherlands, SA due to work-related and not workrelated injuries and illnesses is compensated by the employer. Employers can insure sickness absence compensation and in that case, sickness benefits are paid by the employer's insurer. Employees report sick to their employer, who sends a sick-report to the occupational health service for recording purposes and as a request to start medical guidance of the sick-listed employee. Shortterm SA is self-certified, but medical certification by an OP is required within 6 weeks of reporting sick. The OP not only issues a SA certificate, but also provides both employee and employer with RTW recommendations. Subsequently, the employee and the employer arrange RTW activities, such as accommodated work or transient duties, and agree on a graded-activity scheme of partial RTW. The recovery and RTW process are evaluated every 4-6 weeks in consultation with the OP. After a period of 2 years, an insurance physician scrutinizes the RTW process and assesses the employee's work capacity. If the employee is considered incapable to work despite adequate RTW activities, then a disability pension is granted by the Dutch Social Insurance Agency. 
Ethical Considerations

In legal respect, sickness absence data belong to the employees' companies. Upon contracting, 365/ArboNed asks companies and their work councils for a written consent to use their sickness absence data. Ethical approval was not necessary as the Medical Research involving Human Subjects Act [20] does not apply to studies of anonymised register data. The Medical Ethics Committee of the University Medical Center Groningen confirmed that ethical clearance was not necessary for this study.

Mental Disorders and Return to Work

Mental disorders included 'Symptoms and signs of emotional disturbance' (ICD-10 R45, e.g. nervousness, restlessness, agitation, unhappiness, irritability, demoralization and apathy) as well as the categories of the ICD10 F-chapter 'Mental and behavioral disorders' (Table 1). For this study, OP-certified and ICD-10 classified mental SA was derived from the 365/ArboNed register in the period from January 2006 to December 2008. Return to work (RTW) was defined as resuming work with equal earnings as before SA for at least 28 consecutive days. Since employees were assessed for a disability pension after 2 years, SA was censored if RTW failed to occur within 730 days of reporting sick. All SA episodes were regarded as independent events, even if employees had more than one mental SA episode during the study period.
Covariates

Age, gender and zip codes were retrieved from the 365/ArboNed register. Employees were assigned to the age groups <35 years, 35-44 years, and 45-54 years, and $\geq 55$ years. The zip codes were used to estimate the socioeconomic position (SEP) according to the guidelines of the Netherlands Institute for Social Research [21]. SEP was categorized by quartiles into low, lower average, upper average, and high SEP.

\section{Statistics}

The number of SA episodes, SA incidence and median SA duration were measured per ICD-10 category. RTW percentages were monitored for 2 years in each ICD-10 category. The associations of age, gender and SEP with the time to RTW were analysed with parametric survival models, which account for the changing probability of RTW during SA [22-23]. Different types of parametric models can be distinguished based on the time dependence of the hazard function [23]. A Maximum Likelihood Method strategy [24], performed in Transition Data Analysis (TDA, version 6.4o), showed that log-normal models best fitted the probabilities of RTW in this study. Log-normal parametric survival analyses calculated hazard ratios (HR) and their $95 \%$ confidence intervals (CI), with age $\geq 55$ years, men, and high SEP as reference categories. A HR $>1$ reflected a shorter time to RTW compared to the reference categories and HR is $<1$ a longer time to RTW.

Table 1 Sickness absence (SA) due to mental disorders classified by ICD-10 categories

\begin{tabular}{|c|c|c|c|}
\hline & Episodes N (\%) & Incidence $^{\mathrm{a}}$ & Duration $^{\mathrm{b}}$ \\
\hline R45 Symptoms and signs of emotional disturbance & $17,017(29.8 \%)$ & $18.1(17.9-18.4)$ & $52(51-53)$ \\
\hline F00-09 Organic disorders & n.d. & & \\
\hline F10-19 Psychoactive substance abuse & $418(0.7 \%)$ & $0.4(0.4-0.5)$ & $196(158-234)$ \\
\hline F20-29 Schizophrenia and delusional disorders & $455(0.8 \%)$ & $0.5(0.4-0.5)$ & $278(232-324)$ \\
\hline F30-39 Mood disorders & $7,089(12.4 \%)$ & $7.6(7.4-7.7)$ & $213(206-220)$ \\
\hline F40-49 Neurotic, somatoform and stress-related disorders & $29,754(52.2 \%)$ & $31.7(31.3-32.1)$ & $109(107-111)$ \\
\hline $\begin{array}{l}\text { F50-59 Behavioral syndromes associated with physiological } \\
\text { disturbances and physical factors }\end{array}$ & $756(1.3 \%)$ & $0.8(0.7-0.9)$ & $67(58-76)$ \\
\hline F60-69 Adult personality and behavioral disorders & $627(1.1 \%)$ & $0.7(0.6-0.7)$ & $321(276-366)$ \\
\hline F70-79 Mental retardation & $6(0.0 \%)$ & & \\
\hline F80-89 Disorders of psychological development & n.d. & & \\
\hline F90-98 Disorders of childhood or adolescence onset & n.d. & & \\
\hline F99 Unspecified mental disorders & $904(1.6 \%)$ & $1.0(0.9-1.0)$ & $193(172-214)$ \\
\hline Total SA due to mental disorders & $57,026(100 \%)$ & $60.7(60.2-61.2)$ & $99(98-100)$ \\
\hline
\end{tabular}

n.d. not diagnosed during the period of study

${ }^{\text {a }}$ SA incidence (95\% confidence interval) per 1,000 employees per year

b Median (95\% confidence interval) SA duration in days 


\section{Results}

A total of 51,754 employees (21,146 men and 30,608 women) had 57,026 SA episodes due to mental disorders; $5,272(10 \%)$ employees had more than 1 mental SA episode and 2,644 (5\%) recurrent episodes were diagnosed within the same ICD-10 category as the first SA episode. Between January 2006 and December 2008, SA due to neurotic, somatoform, and stress-related disorders (ICD-10 F40-49) had the highest incidence, followed by SA due to symptoms and signs of emotional disturbance (ICD-10 R45) and SA due to mood disorders (ICD-10 F30-39) as is shown in Table 1. SA due to emotional disturbance (R45) had the shortest median duration and SA due to adult personality disorders (F60-69) the longest median duration.

In total, $26 \%$ of employees with mental disorders resumed work within $1 \frac{1}{2}$ month of reporting sick, $47 \%$ within 3 months, $70 \%$ within 6 months, $87 \%$ within 12 months and $95 \%$ within 24 months; $5 \%$ of employees with mental disorders were assessed for a disability pension. Employees with emotional disturbance (R45) had the highest RTW rates and employees with schizophrenia (F20-29) and adult personality disorders (F60-69) had the lowest RTW rates (Table 2).

Neurotic, somatoform, and stress-related disorders (F4049), emotional disturbance (R45), and mood disorders (F30-39) encompassed $94 \%$ of SA due to mental disorders in the study population. The probability of RTW was high within the first month of reporting sick with emotional disturbance and declined sharply thereafter (Fig. 1). After reporting sick with neurotic disorders, the probability of RTW was high in the first 2 months of SA and decreased thereafter. For mood disorders, the probability of RTW was high in the first 3 months of SA and decreased gradually thereafter.

Of employees with emotional disturbance (R45), $95 \%$ resumed work within 1 year and $98 \%$ within 2 years of reporting sick as compared to 89 and $96 \%$ of employees



Fig. 1 Probability of return to work (RTW) after common mental disorders as a function of time. The figure shows hazard functions representing the probability of RTW on each day after reporting sick with symptoms and signs of emotional disturbance (R45), mood disorders (F30-39) and neurotic, somatoform and stress-related disorders (F40-49)

with neurotic, somatoform, and stress-related disorders (F40-49) and 70 and $86 \%$ respectively of employees with mood disorders (F30-39). Figure 2 shows that the RTW rates of employees with emotional disturbance (R45), neurotic, somatoform, and stress-related disorders (F40-49) were more or less comparable, but differed from the RTW rates of employees with mood disorders (F30-39).

Table 3 shows that the time to RTW was longer $(\mathrm{HR}=0.87)$ in women as compared to men, especially in employees presenting with emotional disturbance (R45), neurotic, somatoform, and stress-related disorders (F4049), and mood disorders (F30-39). Young employees $(<35$ years $)$ resumed work earlier $(\mathrm{HR}=1.08)$ than employees $\geq 55$ years, especially those presenting with emotional symptoms (R45), neurotic, somatoform, and stress-related disorders (F40-49). Age was not significantly

Table 2 Return to work (RTW) percentages at 11/2, 3, 6, 12 and 24 months after reporting sick

\begin{tabular}{|c|c|c|c|c|c|c|}
\hline & $\begin{array}{l}1 \frac{1}{2} \text { month } \\
(\%)\end{array}$ & $\begin{array}{l}3 \text { months } \\
(\%)\end{array}$ & $\begin{array}{l}6 \text { months } \\
(\%)\end{array}$ & $\begin{array}{l}12 \text { months } \\
(\%)\end{array}$ & $\begin{array}{l}24 \text { months } \\
(\%)\end{array}$ & $\begin{array}{l}\text { No RTW } \\
(\%)\end{array}$ \\
\hline Symptoms and signs of emotional disturbance (R45) & 44 & 68 & 85 & 95 & 98 & 2 \\
\hline Psychoactive substance abuse (F10-19) & 17 & 33 & 50 & 72 & 84 & 16 \\
\hline Schizofrenia and delusional disorders (F20-29) & 7 & 18 & 37 & 59 & 76 & 24 \\
\hline Mood disorders (F30-39) & 8 & 22 & 44 & 70 & 86 & 14 \\
\hline Neurotic, somatoform and stress-related disorders (F40-49) & 20 & 44 & 70 & 89 & 96 & 4 \\
\hline $\begin{array}{l}\text { Behavioral syndromes due to physiological disturbances and } \\
\text { physical factors (F50-59) }\end{array}$ & 37 & 57 & 73 & 86 & 93 & 7 \\
\hline Adult personality disorders (F60-69) & 9 & 19 & 34 & 53 & 70 & 30 \\
\hline Unspecified disorders (F99) & 17 & 30 & 49 & 68 & 80 & 20 \\
\hline Total & 26 & 47 & 70 & 87 & 95 & 5 \\
\hline
\end{tabular}




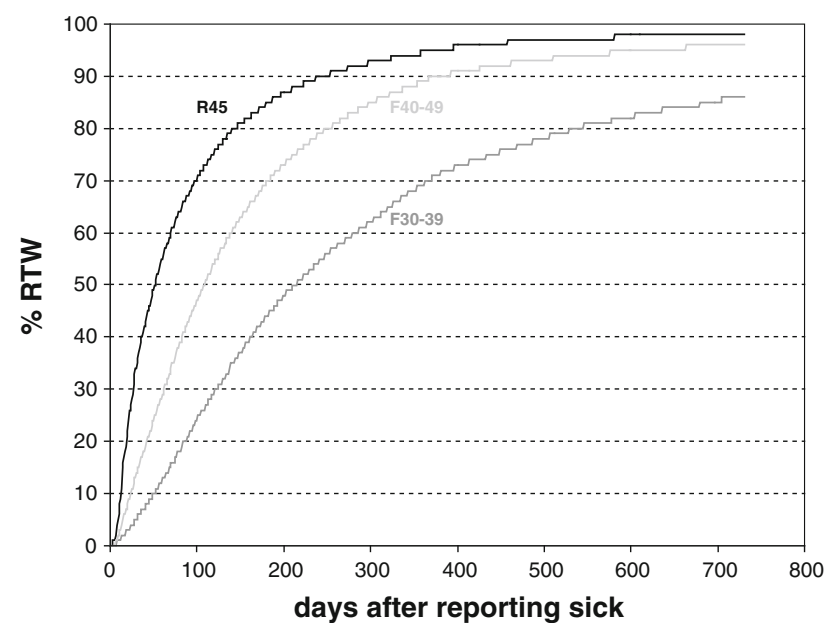

Fig. 2 Return to work (RTW) after common mental disorders stratified by ICD-10 category. The figure shows return to work percentages as a function of time in days after reporting sick with symptoms and signs of emotional disturbance (R45), mood disorders (F30-39) and neurotic, somatoform and stress-related disorders (F40-49)

associated with the time to RTW of employees with mood disorders. Overall, the SEP was not associated with RTW after mental disorders, though low-SEP employees with emotional disturbance (R45), neurotic, somatoform, and stress-related disorders (F40-49) resumed work earlier than high-SEP employees.

\section{Discussion}

Between January 2006 and December 2008, emotional disturbance (R45), neurotic, somatoform, and stress-related disorders (F40-49), and mood disorders (F30-39) constituted $94 \%$ of all mental SA. RTW rates were highest among employees presenting with emotional disturbance (R45) for whom the probability of RTW decreased after 1 month of SA. The probability of RTW decreased after 2 months of SA in employees with neurotic, somatoform, and stress-related disorders (F40-49) and after 3 months of SA in employees with mood disorders (F30-39). Women were longer absent than men in all three categories of most prevalent mental disorders. Younger age and lower socioeconomic position (SEP) were associated with earlier RTW in employees presenting with emotional disturbance (R45) and neurotic, somatoform, and stress-related disorders (F40-49), but not in employees with mood disorders (F30-39).

\section{RTW Rates in Different Categories of Mental Disorders}

This study showed that $44 \%$ of employees with neurotic, somatoform, and stress-related disorders (F40-49) resumed their work within 3 months, leaving $56 \%$ of employees with neurotic disorders still sick-listed after 3 months. After 6 months, $30 \%$ of employees was still sick-listed and after 1 year $11 \%$. Comparison of these RTW rates with those of other studies is limited by the different taxonomies of mental disorders. In a Norwegian study in the late nineties, mental disorders were classified according to the ICPC. Of the employees with neurotic conditions, approximately $50 \%$ was still sick-listed after 3 months, $30 \%$ after 6 months and $9 \%$ after 1 year [12], which is in line with the RTW rates of employees with neurotic, somatoform, and stress-related disorders in the present study.

For mood disorders, however, the RTW rates differed. The Norwegian study reported that $53 \%$ of employees with depressive conditions (ICPC P03, P76, and P77) was still sick-listed at 3 months, $32 \%$ at 6 months and $9 \%$ at 1 year, while in the current study, these percentages were 78,56 , and $30 \%$, respectively. These lower RTW rates may be explained by differences between the ICD-10 and ICPC classification systems. The ICPC was developed to order medical concepts into diagnostic classes relevant for family medicine, while ICD-10 classifies disorders according to the needs of the medical community at large. Although there are some differences, a technical conversion between the ICPC and ICD-10 codes is practically always possible for mental disorders [25-27]. Nystuen et al. categorized feeling depressed (ICPC P03) as a depressive condition, while ICD-10 classifies ICPC P03 in the R45 category of symptoms and signs of emotional disturbance [26-27]. Dutch OPs may also have classified ICPC P03 as a symptom of adjustment disorders with depressive reactions (ICD-10 F43.20-F43.22), which belong to the category of neurotic, somatoform and stressrelated disorders (F40-49). If Dutch OPs only classified the more severe mood disorders as such, this might explain the lower RTW rates among Dutch employees.

Furthermore, the lower RTW rates of employees with mood disorders in The Netherlands may be explained by the different time frames. The Norwegian results originate from the nineties and work has changed considerably since then. For example, work has intensified and is performed with a higher work pace due to higher market constraints and more work pressure due to tight deadlines [17-18]. In 1991, $33 \%$ of European employees perceived high levels of work intensity as compared to $40 \%$ in $1995,42 \%$ in 2000 and $44 \%$ in 2005. Furthermore, $62 \%$ of European people are employed in services, especially high-knowledge services, which is the sector with the highest growth rates, while manufacturing declines in Europe [28]. Hence, work has become more and more mentally demanding and it is conceivable that it takes more time to resume work after a SA episode due to mental disorders. 


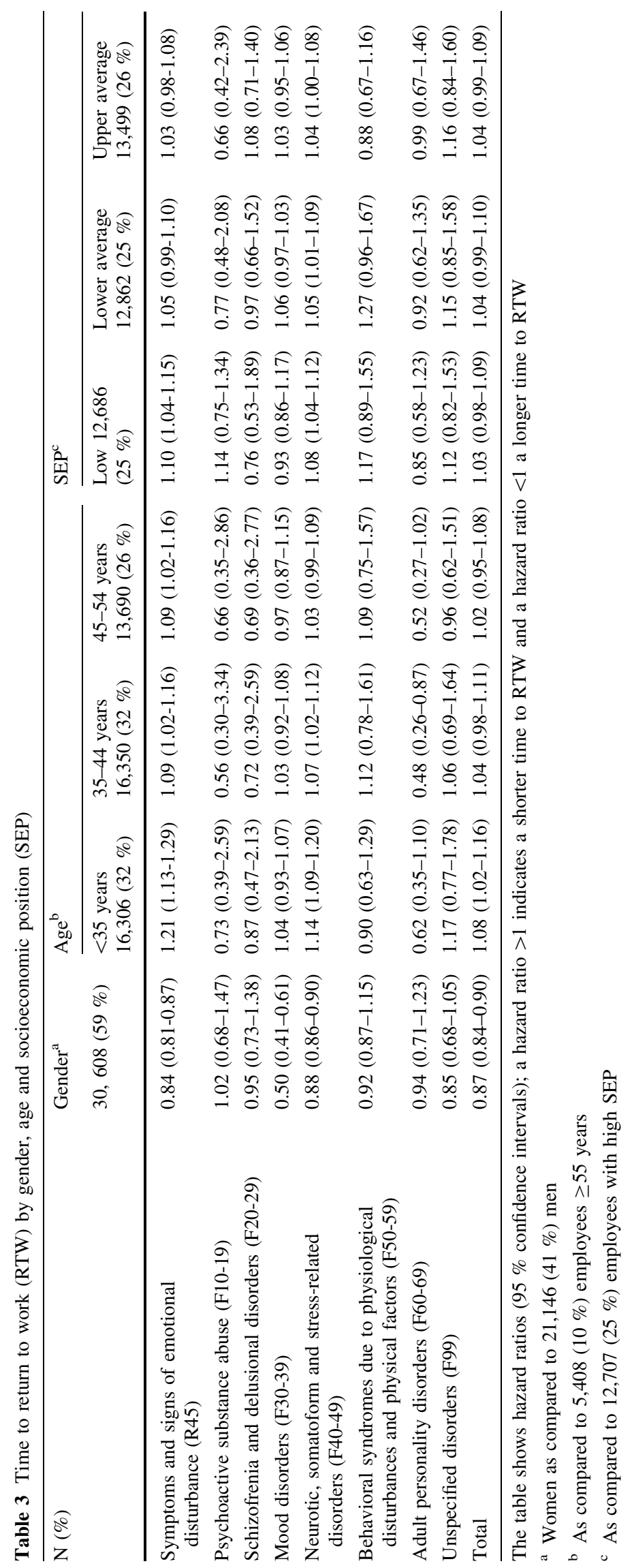


The different RTW rates in employees with mood disorders may also be the result of differences in SA compensation systems. In Norway, employers pay SA benefits in the first 16 calendar days of SA, after which the Norwegian Labour and Welfare Organisation (NLWO) takes over SA compensation. Employees are transferred from sickness benefits to other types of compensation after 1 year of SA in the Norwegian SA compensation system. Comparison of the results shows that similar percentages of Norwegian (9\%) and Dutch (14\%) employees sick-listed with mood disorders are transferred to other types of compensation, such as work allowances or disability pensions. However, in The Netherlands this happens only after 2 years of SA.

To facilitate international comparative studies on SA, there is a need for international consensus on standardized SA measures. Hensing et al. [29] have provided five basic $\mathrm{SA}$ measures for research on the population level. However, international agreement on SA measures on the individual level, for example on the definitions of shortterm and long-term SA, is lacking. Furthermore, SA measures need to be harmonized across countries with different (occupational) healthcare practices and SA compensation policies.

\section{Associations of RTW Rates with Gender and Age}

Women with emotional disturbance (R45), neurotic, somatoform, and stress-related disorders (F40-49) and mood disorders (F30-39) resumed work later than men with these mental disorders. Recent systematic reviews found inconclusive results as to the effects of gender on the duration of SA and the time to RTW in employees with mental health problems [3, 28, 30]. Hensing and Wahlström [3] reported that some studies found a longer duration of SA due to psychiatric disorders in women, while other Nordic studies found longer SA durations in men. Blank et al. [30] found that gender was associated with RTW in 2 out of 15 studies on mental health problems. Cornelius et al. [31] concluded that there was limited evidence ( 1 out of 7 studies) for a gender effect on RTW of employees with mental disorders.

The aforementioned systematic reviews did provide evidence that older age ( $>50$ years) was associated with a longer time to RTW. The current results confirmed that young employees, especially those with emotional disturbance (R45) and neurotic, somatoform, and stress-related disorders (F40-49), returned to work earlier than employees $\geq 55$ years. However, the time to RTW did not differ across age groups in employees with mood disorders (F30-39). The comparison of results was restricted since the literature reviews did not provide data for different types of mental disorder.
Associations of RTW Rates with Socioeconomic Position (SEP)

Recently, Virtanen et al. [32] used the ICD-10 F-chapter to investigate socioeconomic differences in long-term $(\geq 90$ days) psychiatric SA. The authors reported that low SEP was associated with a lower likelihood of RTW in employees with depressive disorders (F32-34), personality disorders (F60-69), schizophrenia (F20-29) and substanceuse disorders (F10-19), but not in employees with bipolar disorders (F30-31), anxiety disorders (F40-42), reactions to severe stress or adjustment disorders (F43). In contrast, the present results showed that low SEP was associated with a higher likelihood of RTW in employees with emotional disturbance (R45) and neurotic, somatoform, and stressrelated disorders (F40-49), while SEP was not related to RTW of employees with mood disorders (F30-39). This study used a contextual (neighbourhood) proxy to estimate the SEP, whereas Virtanen et al. [32] derived the SEP from occupational title classifications. Furthermore, Virtanen et al. subdivided some of the ICD-10 categories. For example, the authors divided the ICD-10 category 'mood disorders' into depressive disorders and bipolar affective disorders. The category 'neurotic, somatoform and stressrelated disorders' was divided into anxiety disorders and adjustment disorders, which may also explain the differences with the current results. Finally, there may be differences between countries, as Nieuwenhuijsen et al. [33] found that a high educational level, which is a proxy for a high SEP, predicted a longer duration until RTW in Dutch employees with mental disorders, which is in line with the current finding of earlier RTW of low-SEP employees presenting with emotional disturbance and neurotic, somatoform, and stress-related disorders.

\section{Practical Implications}

The World Health Organization (WHO) is preparing an 11 th ICD-version in which it is proposed to classify mental disorders into five large groups: (1) neurocognitive disorders, (2) neurodevelopmental disorders, (3) psychoses, (4) internalizing disorders, and (5) externalizing disorders [34]. Internalizing disorders encompass states of anxiety, fear, depression, and somatisation, which share temperamental antecedents, comorbidities and many symptoms. Although there are strong similarities in the overall course of internalizing disorders, the current results showed that employees with neurotic, somatoform, and stress-related disorders (F40-49) had a shorter time to RTW than employees with mood disorders (F30-39). Furthermore, RTW of employees with neurotic, somatoform, and stressrelated disorders (F40-49) was associated with age and SEP, while RTW of employees with mood disorders 
(F30-39) was not related to age or SEP. Researchers in the field of occupational rehabilitation of employees with mental disorders should be aware of such differences before deciding to combine these disorders into 'common mental disorders' or 'mental health problems'.

To our knowledge, this is the first study that presents RTW probabilities on each day of SA due to mental disorders, which may have practical implications for the medical guidance of employees with mental disorders. To maximize the RTW probability in the first months after reporting sick with mental disorders, it is important to consult sick-listed employees in the second or third week of SA, as advised in the guideline for employees with mental health disorders issued by the Netherlands Society of Occupational Medicine [35]. Since the probability of RTW showed a sharp decline after 1 month of SA due to emotional disturbance (R45), focus on RTW is necessary from the onset of OP-guidance. In the first SA weeks, employees with neurotic, somatoform, and stress-related disorders (F40-49) or mood disorders (F30-39) may experience a 'crisis stage' characterized by a loss of coherence and a feeling of not being able to cope with daily activities. In that case, the OP should reassure employees, provide positive perspectives, and recommend a daily structure of activities alternated with relaxation rather than RTW. However, OPs should keep in mind to encourage employees to resume work within the first months of calling in sick.

The results of the study show that it is possible to differentiate between types of mental disorders, for example in defining stagnation in the RTW process and the timing of interventions. Brouwers et al. [36] reported that a long duration of sickness absence before seeking treatment was one of the predictors of a small probability to RTW within 3-6 months of reporting sick with mental disorders. Occupational health providers should consider stagnation in the RTW process of employees sick-listed longer than 1 month with emotional disturbance, 2 months with neurotic, somatoform and stress-related disorders, and 3 months with mood disorders. In that case, the health provider could reconsider the diagnosis, intensify medical guidance or refer the sick-listed employee to therapies with occupational rehabilitation as part of their program. However, more studies are needed to confirm these findings in other settings and countries,

\section{Strengths and Weaknesses of the Study}

An asset of this study was the large number of employees included in the occupational health service register and the availability of recorded SA data free from recall bias [3739]. Although the validity of mental diagnoses in occupational medicine is still being discussed [40], the use of
OP-certified SA is better than relying on employee-reported mental health. In a pilot study among 8,500 post sorters working for the Dutch Postal Services, all 546 employees who reported sick in 2003 consulted an OP and a psychiatrist. There was an $81 \%$ agreement between OPs and psychiatrists on mental disorders as the cause for SA [41]. However, OPs over-diagnosed neurotic, somatoform, and stress-related disorders (F40-49) and under-diagnosed mood disorders (F30-39) as compared to psychiatrists.

The occupational health service register only allowed one ICD-10 code for each SA episode, which is a common weakness in SA register studies [3]. Therefore, information about comorbidity was not available. It is known, however, that comorbid depression and anxiety have a longer SA duration and are stronger related to the risk of disability pension than either depression or anxiety [2]. Also, mental disorders with comorbid physical disorders result in more days off work than mental disorders alone [42]. Another weakness of the study was the limited number of variables in the SA register. For example, information on workrelated and behavioral factors was not available, while it is obvious that these variables affect RTW.

\section{Conclusion}

RTW rates and the probabilities of RTW differed across ICD-10 categories of mental disorders. RTW of employees with emotional disturbance (R45) and neurotic, somatoform, and stress-related disorders (F40-49) was associated with age and SEP, whereas RTW of employees with mood disorders (F30-39) was not related to age and SEP. Physicians should pay attention to RTW activities of employees sick-listed longer than 1 month with emotional disturbance, 2 months with neurotic disorders, or 3 months with mood disorders and refer them, if appropriate, to treatments that include RTW in their programs.

Open Access This article is distributed under the terms of the Creative Commons Attribution License which permits any use, distribution, and reproduction in any medium, provided the original author(s) and the source are credited.

\section{References}

1. ESEMeD. Prevalence of mental disorders in Europe: results from the European study of the epidemiology of mental disorders (ESEMeD) project. Acta Psychiatr Scand. 2004;109(suppl 1): 21-7.

2. ESEMeD. Disability and quality of life impact of mental disorders in Europe: results from the European study of the epidemiology of mental disorders (ESEMeD) project. Acta Psychiatr Scand. 2004;109(suppl 1):38-46.

3. Hensing G, Wahlström R. Sickness absence and psychiatric disorders. Scand J Public Health. 2004;32(suppl 63):152-80. 
4. Hensing G, Andersson L, Brage S. Increase in sickness absence with psychiatric diagnosis in Norway: a general population-based epidemiologic study of age, gender and regional distribution. BMC Med. 2006;4:19.

5. Mykletun A, Overland S, Dahl AA, Krokstad S, Bjerkeset O, Glozier N, Aaro LE, Prince M. A population-based cohort study of the effect of common mental disorders on disability pension awards. Am J Psychiatry. 2006;163:1412-8.

6. Kivimäki M, Ferrie JE, Hakberg J, et al. Diagnosis-specific sick leave as a risk marker for disability pension in a Swedish population. J Epidemiol Community Health. 2007;61:915-20.

7. Vaez M, Rylander G, Nygren $\AA$, Åsberg M, Alexanderson K. Sickness absence and disability pension in a cohort of employees initially on long-term sick leave due to psychiatric disorders in Sweden. Soc Psychiatry Psychiatr Epidemiol. 2007;42:381-8.

8. Bültmann U, Christensen KB, Burr H, Lund T, Rugulies R. Severe depressive symptoms as predictor of disability pension: a 10-year follow-up study in Denmark. Eur J Public Health. 2008;18:23-4.

9. Gjesdal S, Ringdal PR, Haug K, Maeland JG. Long-term sickness absence and disability pension with psychiatric diagnoses: a population-based cohort study. Nord J Psychiatry. 2008;62:294301.

10. Organisation for Economic Co-operation and Development. Transforming disability into ability: policies to promote work and income for disabled people. Paris: OECD; 2003.

11. Nielsen MD, Madsen IEH, Bültmann U, Christensen U, Diderichsen F, Rugulies R. Predictors of return to work in employees sick-listed with mental health problems: findings from a longitudinal study. Eur J Public Health. 2011. doi:10.1093/eurpub/ ckq171.

12. Nystuen P, Hagen KB, Herrin J. Mental problems as a cause of long-term sick leave in the Norwegian workforce. Scand J Public Health. 2001;29:175-82.

13. European Working Condition Surveys. http://www.eurofound. europa.eu/surveys/ewcs/index.htm. Accessed 19 January 2012.

14. Sverke M, Hellgren J, Näswall K. No security: a meta-analysis and review of job insecurity and its consequences. J Occup Health Psychol. 2002;7:242-64.

15. Virtanen M, Kivimäki M, Joensuu M, Virtanen P, Elovainio M, Vahtera J. Temporary employment and health: a review. Int $\mathbf{J}$ Epidemiol. 2005;34:610-22.

16. Virtanen P, Janlert U, Hammarström A. Exposure to temporary employment and job insecurity: a longitudinal study of the health effects. Occup Environ Med. 2011;68:570-4.

17. European Foundation for the Improvement of Living and Working Conditions. Quality of work and employment in Europe: issues and challenges. http://www.eurofound.europa.eu/ pubdocs/2002/12/en/1/ef0212en.pdf. Accessed 19 Jan 2012.

18. European Foundation for the Improvement of Living and Working Conditions. Quality in work and employment. http:// www.eurofound.europa.eu/pubdocs/2005/129/en/1/ef05129en. pdf. Accessed 19 Jan 2012.

19. World Health Organisation. International classification of diseases and related health problems: ICD-10. Geneva: WHO; 1994.

20. WMO (2000) The Medical Research involving Human Subjects Act. http://www.healthlaw.nl/humsub.pdf. Accessed 19 Jan 2012.

21. Netherlands Institute for Social Research. http://www.scp.nl/ onderzoek/statusscores. Accessed 19 Jan 2012.

22. Christensen KB, Andersen PK, Smith-Hansen L, Nielsen ML, Kristensen TS. Analyzing sickness absence with statistical models for survival data. Scand J Work Environ Health. 2007;33:233-9.

23. Koopmans PC, Roelen CAM, Groothoff JW. Parametric hazard rate models for long-term sickness absence. Int Arch Occup Environ Health. 2009;82:575-82.
24. Lawless JF. Statistical models and methods for lifetime data. New York: Wiley-Interscience; 1982.

25. Wood M, Lamberts H, Meijer JS, Hofman-Okkes IM. The conversion between ICPC and ICD-10. Requirements for a family of classification systems in the next decade. Fam Pract. 1992; 9:340-8.

26. Lamberts H, Magruder K, Kathol RG, Okkes I. The classification of mental disorders in primary care: a guide through a difficult terrain. Int J Psychiatry Med. 1998;28:159-76.

27. Lamberts H, Hofmans-Okkes IM. The classification of psychological and social problems in general practice. http://www. transitieproject.nl/Documentation/Full\%20Text\%20Bib126.Pdf. Accessed 03 Feb 2012.

28. European Working Conditions Surveys. http://www.eurofound. europa.eu/pubdocs/2005/129/en/1/ef05129en.pdf. Accessed 03 Feb 2012.

29. Hensing G, Alexanderson K, Allebeck P, Bjurulf P. How to measure sickness absence? Literature review and suggestion of five basic measures. Scand J Soc Med. 1998;26:133-44.

30. Blank L, Peters J, Pickvance S, Wilford J, McDonald J. A systematic review of the factors which predict return to work for people suffering episodes of poor mental health. J Occup Rehabil. 2008;18:27-34.

31. Cornelius LR, van der Klink JJL, Groothoff JW, Brouwer S. Prognostic factors of long-term disability due to mental disorders: a systematic review. J Occup Rehabil. 2011;21:259-74.

32. Virtanen M, Kawachi I, Oksanen T, Salo P, Tuisku K, PulkkiRåback L, Pentti J, Elovainio M, Vahtera J, Kivimäki M. Socieconomic differences in long-term psychiatric disability: prospective cohort study of onset, recovery, and recurrence. Occup Environ Med. 2011;68:791-8.

33. Nieuwenhuijsen K, Verbeek JH, de Boer AG, Blonk RW, van Dijk FJ. Predicting the duration of sickness absence for patients with common mental disorders in occupational healthcare. Scand J Work Environ Health. 2006;32:67-74.

34. Goldberg D. Should our major classifications of mental disorders be revised? Br J Psych. 2010;196:255-6.

35. Guideline Mental Health Disorders. Available from http://nvab. artsennet.nl/Artikel-3/Psychische-Problemen.htm. [in Dutch].

36. Brouwers EP, Terluin B, Tiemens BG, Verhaak PF. Predicting return to work in employees sick-listed due to minor mental disorders. J Occup Rehabil. 2009;19:323-32.

37. Van Poppel M, de Vet H, Koes B, Smid T, Bouter L. Measuring sick leave: a comparison of self-reported data on sick leave and data from company records. Occup Med. 2002;52:485-90.

38. Ferrie JE, Kivimäki M, Head J, Shipley MJ, Vahtera J, Marmot MG. A comparison of self-reported sickness absence with absences recorded in employers' registers: evidence from the Whitehall II study. Occup Environ Med. 2005;62:74-9.

39. Voss M, Stark S, Alfredsson L, Vingård E, Josephson M. Comparisons of self-reported and register data on sickness absence among public employees in Sweden. Occup Environ Med. 2008;65:61-7.

40. O’Niell E, McNamee R, Agius R, Gittins M, Hussey L, Turner S. The validity and reliability of diagnoses of work-related mental ill-health. Occup Environ Med. 2008;65:726-31.

41. Hoogduin CAL, van Leusden R. Management of sickness absence: successes. Amsterdam: Boom; 2006.

42. Buist-Bouwman MA, de Graaf R, Vollebergh WA. Ormel J Comorbidity of physical and mental disorders and the effect of work-loss days. Acta Psychiatr Scand. 2005;111:436-43. 